\title{
Risk factors for leg harvest surgical site infections after coronary artery bypass graft surgery
}

\author{
Margaret A. Olsen, $\mathrm{MPH}, \mathrm{PhD}^{\mathrm{a}}$ \\ Thoralf M. Sundt, $M D^{b}$ \\ Jennifer S. Lawton, $\mathrm{MD}^{\mathrm{c}}$ \\ Ralph J. Damiano, Jr, MD ${ }^{\mathrm{c}}$ \\ Diane Hopkins-Broyles, BSN, CIC $^{d}$ \\ Patricia Lock-Buckley, RHIT \\ Victoria J. Fraser, MD ${ }^{\mathrm{a}}$
}

From the Division of Infectious Diseases,
Department of Internal Medicine, Washing-
ton University School of Medicine, ${ }^{\mathrm{a}}$ St
Louis, Mo, the Department of Surgery,
Mayo Clinic, ${ }^{\mathrm{b}}$ Rochester, Minn, the Depart-
ment of Surgery, Washington University
School of Medicine, ${ }^{\mathrm{c}}$ St Louis, Mo, and the
Department of Infection Control, Barnes-
Jewish Hospital, ${ }^{\mathrm{d}}$ St Louis, Mo.

Supported by the Centers for Disease Control Cooperative Prevention Epicenters Agreement \#UR8/CCU715087-01.

Received for publication Sept 19, 2002; revisions requested Oct 25, 2002; revisions received Dec 23, 2002; accepted for publication Dec 27, 2002.

Address for reprints: Margaret A. Olsen, $\mathrm{MPH}, \mathrm{PhD}$, Washington University School of Medicine, Division of Infectious Diseases, 660 South Euclid Ave, Campus Box 8051, St Louis, MO 63110-1093 (E-mail: molsen@im.wustl.edu).

J Thorac Cardiovasc Surg 2003;126:992-9

Copyright $\odot 2003$ by The American Association for Thoracic Surgery

$0022-5223 / 2003 \$ 30.00+0$

doi:10.1016/S0022-5223(03)00200-9
Objective: Harvest site infections are more common than chest surgical infections after coronary artery bypass surgery, yet few studies detail risk factors for these infections. We sought to determine independent risk factors for leg surgical site infections using our institutional Society of Thoracic Surgeons database.

Methods: We retrospectively analyzed data collected from 1980 coronary artery bypass patients undergoing surgery at our institution from January 1, 1996, through June 30, 1999, using The Society of Thoracic Surgeons database. Independent risk factors for leg harvest site infection were identified by multivariate logistic regression.

Results: Seventy-six patients $(4.5 \%)$ were coded as having had a leg harvest site infection, of which 67 were confirmed by infection control. The length of hospital stay after surgery was significantly longer in patients with leg harvest site infection (mean 10.1 days) compared with that of patients without infection (mean 7.1 days, $P<.001$ ), and infected patients were more likely to be readmitted to the hospital within 30 days of surgery. Independent risk factors for leg harvest site infection included previous cerebrovascular accident (odds ratio, 2.9), postoperative transfusion of 5 units or more of red blood cells (odds ratio, 2.8), obesity (odds ratio, 2.5), age 75 years or older (odds ratio, 1.9), and female gender (odds ratio, 1.8).

Conclusions: Consistent with previous studies, female gender and obesity were identified as independent risk factors for leg harvest site infection, while previous cerebrovascular accident, postoperative transfusion, and older age are newly described risk factors. The Society of Thoracic Surgeons database is a useful tool for identification of predictors of leg harvest site infections.

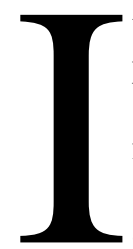
$\mathrm{t}$ is estimated that $2 \%$ to $20 \%$ of coronary artery bypass grafting (CABG) procedures in the United States are complicated by surgical site infections (SSI) at the sternal or conduit harvest site incisions. ${ }^{1}$ Most attention has focused on deep chest infections and mediastinitis due to their potential for serious morbidity and mortality, although graft harvest site infections may actually be more common after CABG. ${ }^{1-4}$ Formal studies to determine the impact of leg harvest site infections on length of hospital stay and costs have not been performed, but an early study by DeLaria and coworkers ${ }^{5}$ showed that leg wound complications resulted in a mean of 12 additional days in the hospital and increased hospital costs by $\$ 9900$. Thus, it is likely that leg harvest site infections not only result in increased morbidity for patients, but also increase the length of hospital stay and hospital costs. 
Few studies have been published that have included an analysis of risk factors specifically for harvest site infection in CABG patients. The majority of the literature concerning SSI in CABG patients has focused either on sternal wound infections or has involved an analysis of all wound infections occurring after surgery (combining chest and harvest sites together). To identify patients at increased risk of these infections and to devise strategies to reduce their risk, it is important to determine specific risk factors for leg harvest site infections. This may be of particular relevance as new, less invasive but more expensive technologies are developed for conduit harvest.

Risk factors for leg harvest site infection that have been identified in previous studies include obesity, ${ }^{6-8}$ female gender, ${ }^{7,9}$ diabetes, ${ }^{7}$ wound depth, ${ }^{10}$ continuous open incision method of harvesting the saphenous vein(s), ${ }^{7,11}$ and wound length. ${ }^{12}$ Numerous studies have reported risk factors for leg wound complications or impaired wound healing that presumably correlate with risk of leg harvest site infection. The variety of risk factors for leg wound complications or impaired healing reported include female gender, ${ }^{5,13,14}$ diabetes, ${ }^{13,15}$ obesity, ${ }^{13,15}$ peripheral vascular disease, ${ }^{13,14}$ left ventricular end-diastolic pressure greater than $15 \mathrm{~mm} \mathrm{Hg},{ }^{13}$ longer crossclamp time, ${ }^{16}$ postoperative placement of an intra-aortic balloon pump, ${ }^{14}$ postoperative treatment with nicardipine, ${ }^{17}$ lack of postoperative treatment with dobutamine or nitroglycerin, ${ }^{17}$ leg incision open more than 150 minutes ${ }^{17}$ and the traditional open method of saphenous vein harvest (compared with endoscopic harvest). ${ }^{15,18,19}$ It is difficult to interpret the relevance of some of these reported risk factors for leg wound complications due to the heterogeneous nature of the wound complications included in the published studies.

We used our institutional Society of Thoracic Surgeons (STS) Adult Cardiac Surgery database to analyze the influence of various potential risk factors on the incidence of leg harvest site infection. The national STS database was established for the purpose of risk stratification for mortality after cardiac surgery, and thus the variables available for analysis are those related to the primary outcome of mortality, including a variety of underlying medical, operative, and postoperative conditions and processes of care. We used the variables in this database to determine independent risk factors for leg harvest site infections in patients undergoing CABG surgery, and to determine the effect of these infections on duration of hospital stay and mortality.

\section{Methods}

All patients $(\mathrm{n}=1980)$ undergoing CABG at Barnes-Jewish Hospital between January 1,1996, and June 30, 1999, were included. Preoperative demographics, operative details, and postoperative complications were derived from our institutional STS Adult Cardiac Surgery database. Our institutional STS database contains a variety of additional variables that are not present in the national database relevant to postoperative infections, such as type and timing of prophylactic antibiotics and the number of units of transfused blood products. Data concerning antibiotic treatment of leg harvest site infections and hospital readmissions were collected from the Barnes-Jewish Hospital Informatics database. Leg harvest site infections were verified via the hospital's infection control database, which is maintained separately from the STS database by the Infection Control Department in accordance with the Centers for Disease Control guidelines. Discrepant results were reconciled using the patient's medical record. Subjects were excluded from the study only if data for variables found important in the multivariate analyses were missing.

Risk factor analyses were performed using the total number of leg harvest site infections in the STS database and separately for confirmed leg infections meeting the National Nosocomial Infections Surveillance (NNIS) criteria with symptoms occurring within 30 days of surgery. Deep leg harvest site infections involved the fascial or muscle layers of the incision and must have been accompanied by purulent drainage, spontaneous dehiscence, or intentional opening by a surgeon in a patient with fever, local pain, or tenderness, abscess or other evidence of deep infection, or diagnosis of a deep leg harvest site infection by a physician. Superficial leg harvest site infections involved only the skin or subcutaneous layers of the incision, and must have included purulent drainage, isolation of microorganisms from an aseptically obtained culture, diagnosis of a superficial leg harvest site infection by a physician, or at least one of the following: pain, tenderness, edema in the area of the incision, erythema, or intentional opening of the incision by the surgeon. Leg infections were defined by STS during the time period of data collection (January 1996 through June 1999) as infections involving a leg vein harvest site, including at least one of the following: (1) wound opened with excision of tissue, (2) positive wound culture, and/or (3) treatment with antibiotics. Postdischarge surveillance on all patients was performed 30 days after surgery to identify leg infections that occurred in the outpatient setting by telephone contact with both the cardiothoracic surgeon and the referring physician's offices.

Potential risk factors for leg harvest site infection analyzed included the following: (1) history of diabetes (including method of treatment), (2) congestive heart failure (including severity and previous myocardial infarction), (3) renal failure, (4) hypertension, (5) hypercholesterolemia, (6) peripheral vascular disease, and (7) cerebrovascular accident (or transient ischemic attack).

Baseline characteristics tested included body mass index (BMI, weight in kilograms/(height in meters) ${ }^{2}$ ), smoking history, previous cardiac surgical and nonsurgical interventions, length of hospital stay before surgery, use of inotropic drugs before surgery, diseased number of vessels, and use of various preoperative medications. Operative or postoperative variables included the number and type of blood transfusions received before, during, and after surgery; use of internal thoracic artery grafts; use of intra-aortic balloon pumping; operative status; aortic crossclamp time; time on bypass; duration of antibiotic prophylaxis before incision; number of conduits; and mortality after surgery.

Since risk factors for leg harvest site infection may also be risk factors for other types of infections, control patients for all the univariate and multivariate analyses were restricted to those patients with no identified infection in the STS database within 30 
days of surgery. Thus, patients with sepsis, pneumonia, urinary tract infection, or any other SSI (chest, radial artery, and intraaortic balloon pump site) were excluded from the control population.

Statistical analyses were performed in SPSS 11.0 software (SPSS, Inc, Chicago, Ill). Univariate analyses were performed for all relevant categorical variables using contingency tables $\left(\chi^{2}\right.$ or Fisher exact test for variables with small expected cell numbers), and $t$ tests or the Mann-Whitney $U$ test for continuous variables. Multivariate analyses were performed by logistic regression in which all variables with $P<.10$ in the univariate analyses, or previously shown to be related to surgical site infection from the literature, were included in the initial models. All 2-way interaction factors involving categorical variables that were deemed relevant were tested in the models after selection of the independent risk factors (main effects) and were included in the final models only if they were significant $(P<.05) .{ }^{20}$ The final models were judged to be a good fit for the data by the Hosmer and Lemeshow goodness-of-fit test.

\section{Results}

\section{Incidence of Leg Harvest Site Infection and Microbiology}

During the time of the study, 1980 patients had CABG surgery (CABG only or CABG plus an additional cardiac procedure), and saphenous vein grafts were used in 1500 patients (75.8\%). Traditional open methods for harvest of saphenous vein(s) were used exclusively during this study. Veins were harvested preferentially from the upper thigh (when possible, exclusively upper thigh harvest in diabetic patients and those with peripheral vascular disease), using approximately 4-inch incisions and multiple skin bridges. Longer incisions were used to harvest saphenous veins in morbidly obese patients and in patients whose veins were very superficial. Cefazolin was used for prophylaxis in $81 \%$ of patients (a preincision dose plus 3 postoperative doses at 8 -hour intervals), while vancomycin was used in the remaining $19 \%$ of patients (a preincision dose plus 2 postoperative doses at 12 -hour intervals). All patients received the same prophylactic regimen, regardless of the type of surgery.

Seventy-five patients had leg harvest site infections according to our STS database, with one additional patient identified by the hospital infection control specialist (total number of leg harvest site infections $=76$ ). Sixty-seven leg harvest site infections were confirmed by the infection control specialists, resulting in an incidence of $4.5 \%$ confirmed infections and $5.1 \%$ total leg harvest site infections during the study period. No outbreaks of leg harvest site infection were recognized during the study period, and the yearly incidence did not vary significantly with time (range 4.8$7.1 \%, P=.755)$.

Eight of the 67 confirmed leg harvest site infections were characterized as deep incisional infections by the infection control specialist, 56 were superficial infections, and 3 were not characterized as to depth. The 9 harvest site infections that were not confirmed by the infection control specialists all occurred in the outpatient setting and were presumably superficial infections. Thirty-six of the total 75 leg harvest site infections (48\%) were diagnosed and treated solely in an outpatient setting, while the remaining 39 patients were hospitalized for therapy of their infection. Positive bacterial cultures were obtained from only 25 patients, 12 of which contained mixed flora (3 or more species). Staphylococcus aureus was isolated in pure culture from 5 patients and was present in an additional 4 specimens with other bacteria. Gram-negative bacilli were identified in 11 of the 25 positive cultures.

The 8 patients with confirmed deep leg harvest site infections and the 3 patients with infections of unknown depth were all treated with intravenous antibiotics, whereas 26 of the patients with superficial leg harvest site infections were also treated with intravenous antibiotics (alone or in combination with oral antibiotics). Thirty of the patients with confirmed superficial leg harvest site infections were treated exclusively with oral antibiotics; 27 of the 30 patients were treated as outpatients, and 3 were treated with oral antibiotics in the hospital.

\section{Risk Factors Identified by Univariate Analyses}

For all statistical analyses, the potential risk factors for the 76 patients with leg harvest site infections were compared with the risk factors in patients with saphenous vein donor grafts who were free of recognized infection (as defined by the STS database) during the month after surgery $(\mathrm{n}=$ 1200). We excluded 227 patients with other postoperative infections from the control group, since risk factors for one type of infection may also be risk factors for leg harvest site infection.

Results of the univariate analyses for categorical risk factors found to be significantly associated with total leg harvest site infection are shown in Table 1, and the results for continuous variables are shown in Table 2 . Significantly increased risk of leg harvest site infection was associated with age 75 years or older; female gender; obesity (BMI between 30 and 35), and morbid obesity (BMI > 35); a history of congestive heart failure, cerebrovascular accident, or insulin-dependent diabetes; circulatory arrest during surgery; and receipt of 5 to 6 units of packed red blood cells postoperatively (Table 1).

In the analysis of continuous variables, infected patients were significantly older and had higher BMI and predicted mortality (based on the STS algorithm) than uninfected control patients with saphenous vein harvest(s) (Table 2). Patients with leg harvest site infections received a larger number of units of packed red blood cell transfusions, both in the postoperative period and throughout their hospital stay (Table 2). Infected patients also had significantly longer postoperative length of hospital stay during the original 
TABLE 1. Univariate comparisons of risk factors in patients with and without leg harvest site infection

\begin{tabular}{|c|c|c|c|c|}
\hline Risk factor & $\begin{array}{l}\text { Patients (n= } 76 \text { ) } \\
\text { with leg harvest } \\
\text { site infection }(\%)\end{array}$ & $\begin{array}{l}\text { Uninfected patients } \\
(\mathrm{n}=1200)(\%)\end{array}$ & $\begin{array}{c}\text { Odds ratio ( } 95 \% \\
\text { confidence interval) }\end{array}$ & $\boldsymbol{P}$ \\
\hline Age 75 or older & $30(39.5)$ & $293(24.4)$ & $2.0(1.3,3.3)$ & .003 \\
\hline Gender (female) & $40(52.6)$ & $396(33.0)$ & $2.3(1.4,3.6)$ & $<.001$ \\
\hline \multicolumn{5}{|l|}{ Underlying diseases/conditions } \\
\hline \multicolumn{5}{|l|}{ Body mass index } \\
\hline$\leq 25$ & $18(23.7)$ & $355(29.6)$ & Reference & \\
\hline $25-30$ & $21(27.6)$ & $508(42.3)$ & $0.8(0.4,1.6)$ & .534 \\
\hline $30-35$ & $24(31.6)$ & $215(17.9)$ & $2.2(1.2,4.2)$ & .015 \\
\hline$>35$ & $13(17.1)$ & $122(10.2)$ & $2.1(1.0,4.4)$ & .050 \\
\hline Aspirin therapy before surgery & $54(71.1)$ & $950(79.6)$ & $0.6(0.4,1.1)$ & .077 \\
\hline Congestive heart failure & $32(42.7)$ & $375(31.3)$ & $1.6(1.0,2.6)$ & .040 \\
\hline Cerebrovascular accident & $16(25.0)$ & $122(10.2)$ & $2.9(1.7,5.1)$ & $<.001$ \\
\hline \multicolumn{5}{|l|}{ Diabetes } \\
\hline No history & $37(48.7)$ & $751(62.8)$ & Reference & \\
\hline Diet or no medication & $6(7.9)$ & $67(5.6)$ & $1.8(0.7,4.5)$ & .192 \\
\hline Oral medication & $13(17.1)$ & $195(16.3)$ & $1.4(0.7,2.6)$ & .363 \\
\hline Insulin medication & $20(26.3)$ & $183(15.3)$ & $2.2(1.3,3.9)$ & .006 \\
\hline Pulmonary hypertension & $10(13.2)$ & $92(7.7)$ & $1.8(0.9,3.7)$ & .087 \\
\hline \multicolumn{5}{|l|}{ Operative risk factors } \\
\hline Valve surgery in addition to $\mathrm{CABG}$ & $16(21.1)$ & $156(13.0)$ & $1.8(1.0,3.2)$ & .046 \\
\hline Circulatory arrest during surgery & $5(6.6)$ & $16(1.3)$ & $5.2(1.9,14.6)$ & .006 \\
\hline Intraoperative cryoprecipitate & $4(5.3)$ & $22(1.8)$ & $3.0(1.0,8.9)$ & .064 \\
\hline Intraoperative packed red blood cells & $49(64.5)$ & $642(53.5)$ & $1.6(1.0,2.6)$ & .063 \\
\hline \multicolumn{5}{|c|}{ Postoperative packed red blood cell transfusions } \\
\hline None & $15(19.7)$ & $372(31.0)$ & Reference & \\
\hline $1-2$ units & $32(42.1)$ & $497(41.4)$ & $1.6(0.9,3.0)$ & .144 \\
\hline 3-4 units & $11(14.5)$ & 214 (17.8) & $1.3(0.6,2.8)$ & .550 \\
\hline 5-6 units & $13(17.1)$ & $57(4.8)$ & $5.7(2.6,12.5)$ & $<.001$ \\
\hline$\geq 7$ units & $5(6.6)$ & $60(5.0)$ & $2.1(0.7,5.9)$ & .175 \\
\hline
\end{tabular}

surgical admission than the uninfected control patients, with a mean additional length of stay of 3.0 days attributable to leg harvest site infection (Table 2). Additionally, patients with leg harvest site infections were readmitted to the hospital within 30 days of the surgical procedure more frequently than uninfected control patients (24/76 patients with leg harvest site infections were readmitted within 30 days vs 126/1200 uninfected patients, $P<.001$ ). Leg wound infection was the primary reason for hospitalization in two thirds $(16 / 24)$ of the readmitted patients with leg harvest site infections. No patients with leg harvest site infections died during the first month after surgery, and there was no increase in documented mortality in the first year after surgery, in comparison to patients with no infections after CABG (3 deaths/76 patients with leg harvest site infections vs 99 deaths $/ 1200$ uninfected patients, $P=.180, \chi^{2}$ test).

Although insulin-dependent diabetes was associated with only a marginally increased risk of leg harvest site infection (Table 1), a history of cerebrovascular accident in patients with insulin-dependent diabetes was associated with a greatly increased risk of leg harvest site infection by univariate analysis (odds ratio 8.1, 95\% confidence interval: $3.7,17.9, P<.001)$. There was also a significant trend toward increasing risk of peripheral vascular disease in patients with both a history of previous cerebrovascular accident and insulin-dependent diabetes compared with patients with only one illness or neither previous cerebrovascular accident or insulin-dependent diabetes $(P$ for linear trend $<.001)$.

\section{Independent Risk Factors of Leg Harvest Site Infection}

Multivariate logistic regression was used to identify independent risk factors for leg harvest site infection. Circulatory arrest during surgery was associated with the greatest risk of total leg harvest site infection (adjusted odds ratio 3.9), although the confidence interval for this estimate is large due to the small number of infected patients with circulatory arrest (Table 3). Postoperative transfusion with 5 or more units of packed red blood cells, previous cerebrovascular accident, BMI greater than 30, age over 75 years, and female gender were additional independent risk factors for total leg harvest site infection.

The multivariate analysis was also performed using confirmed leg harvest site infections as the outcome. The independent risk factors identified in this analysis were very 
TABLE 2. Univariate analysis of continuous variables as risk factors for leg harvest site infections after CABG surgery

\begin{tabular}{|c|c|c|c|c|c|}
\hline \multirow[b]{2}{*}{ Risk factor } & \multicolumn{2}{|c|}{ Mean ( \pm SD) } & \multicolumn{2}{|c|}{ Median (range) } & \multirow[b]{2}{*}{$P^{*}$} \\
\hline & $\begin{array}{l}\text { Patients with leg } \\
\text { harvest infection }\end{array}$ & $\begin{array}{l}\text { Uninfected } \\
\text { patients }\end{array}$ & $\begin{array}{l}\text { Patients with leg } \\
\text { harvest infection }\end{array}$ & $\begin{array}{l}\text { Uninfected } \\
\text { patients }\end{array}$ & \\
\hline Age & $69.6(10.6)$ & $66.3(10.8)$ & $71.5(45-90)$ & $68(34-94)$ & .013 \\
\hline Body mass index & $30.0(5.8)$ & $28.0(5.1)$ & $29.8(20.0-48.5)$ & $27.3(15.3-53.1)$ & .003 \\
\hline Ejection fraction & $39.1(15.2)$ & $42.7(14.9)$ & $35(10-80)$ & $40(5-90)$ & .051 \\
\hline Length of stay before surgery & $3.4(3.2)$ & $3.0(3.3)$ & $2(0-18)$ & $2(0-33)$ & .179 \\
\hline Predicted mortality† & $6.1(9.8)$ & $4.6(7.5)$ & $3.2(0.7-59.6)$ & $2.4(0.2-81.4)$ & .014 \\
\hline Time of antibiotic prophylaxis before incision $\ddagger$ (min) & $71.0(32.0)$ & $65.9(40.9)$ & $70(10-176)$ & $65(-35-588)$ & .139 \\
\hline Crossclamp time§ (min) & $94.9(39.2)$ & $88.6(35.9)$ & $87.5(36-225)$ & $(12-397)$ & .236 \\
\hline Time on CPB $\|(\min )$ & $150.5(49.3)$ & $148.3(52.2)$ & $142(66-317)$ & $(35-571)$ & .650 \\
\hline Lowest core temperature $\left({ }^{\circ} \mathrm{C}\right)$ & $31.0(3.7)$ & $31.4(2.7)$ & $32(15-37)$ & $32(15-38)$ & .830 \\
\hline Number of conduits used & $3.1(1.1)$ & $3.2(1.0)$ & $3(1-6)$ & $3(1-6)$ & .385 \\
\hline Postoperative units of packed RBCs & $2.6(2.2)$ & $2.3(4.5)$ & $2(0-9)$ & $2(0-90)$ & .005 \\
\hline Total units of packed RBCs transfused & $4.6(3.8)$ & $3.9(6.6)$ & $4(0-22)$ & $3(0-105)$ & .001 \\
\hline Length of stay after surgery & $10.1(7.5)$ & $7.1(5.3)$ & $7(3-43)$ & $6(0-75)$ & $<.001$ \\
\hline
\end{tabular}

*Compared with control patients with no infection during the 30 days after surgery, Mann-Whitney $U$ test.

tCalculated by the STS algorithm.

$\ddagger$ Data available for 52 infected and 919 uninfected patients.

§Comparison only for patients in which the crossclamp time $>0$.

\|Comparison only for patients with on-pump procedure (perfusion time $>0$ ).

TABLE 3. Multivariate analysis of independent risk factors for total leg harvest site infections and confirmed leg harvest site infections

\begin{tabular}{|c|c|c|c|c|}
\hline \multirow[b]{2}{*}{ Risk factor } & \multicolumn{2}{|c|}{ Total leg infections $(n=76)$} & \multicolumn{2}{|c|}{ Confirmed leg infections $(n=67)$} \\
\hline & Adjusted odds ratio $(95 \mathrm{Cl})^{*}$ & $\boldsymbol{P}$ & Adjusted odds ratio (95 $\mathrm{Cl}) \dagger$ & $\boldsymbol{P}$ \\
\hline Circulatory arrest during surgery & $3.9(1.3,11.8)$ & .017 & & \\
\hline Previous cerebrovascular accident & $2.9(1.6,5.2)$ & $<.001$ & $2.8(1.5,5.1)$ & .001 \\
\hline$\geq 5$ units packed red blood cells postoperatively & $2.8(1.5,5.0)$ & .001 & $3.1(1.7,5.7)$ & $<.001$ \\
\hline Obesity (BMI $\geq 30$ ) & $2.5(1.5,4.2)$ & $<.001$ & $2.6(1.5,4.3)$ & $<.001$ \\
\hline Age 75 years or older & $1.9(1.1,3.2)$ & .013 & $2.1(1.2,3.6)$ & .006 \\
\hline Female gender & $1.8(1.1,3.0)$ & .014 & $1.6(0.9,2.6)$ & .095 \\
\hline Aspirin therapy before surgery & & & $0.6(0.3,1.0)$ & .047 \\
\hline
\end{tabular}

${ }^{*}$ Adjusted odds ratios for various risk factors using as the outcome the total leg harvest site infections (67 confirmed plus 9 infections that occurred in the outpatient setting, that were not confirmed by the infection control specialists).

tAdjusted odds ratios for various risk factors using only the 67 leg harvest site infections confirmed by the infection control specialists as the outcome in the multivariate analysis.

similar to those identified for total leg harvest site infections, although circulatory arrest was excluded due to the small number of patients with confirmed infections who underwent circulatory arrest during surgery $(n=4)$. In addition, preoperative aspirin therapy was independently associated with significantly lower risk of leg harvest site infection when the analysis was restricted to confirmed infection, and female gender conferred only a marginally increased risk of infection. After controlling for aspirin therapy, the risk of confirmed leg harvest site infection attributable to female gender was decreased (Table 3). Preoperative aspirin use was noted to be significantly higher in male than female patients $(81.6 \%$ in men vs $74.1 \%$ in women, $P=.002)$.
Interaction effects were also tested in the multivariate models to determine whether combinations of risk factors conferred greater risk of leg harvest site infection that would be predicted from the additive effects of the individual risk factors alone. As described above in the univariate analysis, the interaction of previous cerebrovascular accident and insulin-dependent diabetes was associated with significantly increased risk of total leg harvest site infection. This interaction remained significant after controlling for the other independent risk factors of total leg harvest site infection (Table $4, P=.035$ for interaction). The interaction did not remain significant in the model using confirmed leg harvest site infections as the outcome, however $(P=.132$ for interaction). 
TABLE 4. Previous cerebrovascular accident confers a higher risk of total leg harvest site infection in insulin-dependent diabetic patients than in patients with no history of insulin-dependent diabetes

\begin{tabular}{|c|c|c|c|}
\hline $\begin{array}{l}\text { Combination of insulin-dependent } \\
\text { diabetes and previous } \\
\text { cerebrovascular accident }\end{array}$ & $\begin{array}{c}\text { Infected patients/ } \\
\text { total (\%) }\end{array}$ & $\begin{array}{l}\text { Adjusted odds } \\
\text { ratios* }(95 \% \mathrm{CI})\end{array}$ & $\boldsymbol{P}$ \\
\hline Neither & 47/958 (4.9) & 1.0 & \\
\hline History of CVA only & $9 / 107(8.4)$ & $1.8(0.9,4.0)$ & .118 \\
\hline Insulin-dependent diabetes only & $8 / 169(5.9)$ & $1.0(0.5,2.1)$ & .967 \\
\hline $\begin{array}{l}\text { Both CVA and insulin-dependent } \\
\text { diabetes }\end{array}$ & $10 / 34(29.4)$ & $7.2(3.1,16.9)$ & $<.001$ \\
\hline
\end{tabular}

${ }^{*}$ Odds ratios adjusted for circulatory arrest (adjusted $\mathrm{OR} 4.0 ; 95 \% \mathrm{Cl}: 1.3,12.4$ ), postoperative transfusion with 5 or more units of packed red blood cells (adjusted OR 2.8; 95\% Cl: 1.5, 5.1), obesity (adjusted OR 2.5; 95\% Cl: 1.5, 4.2), age over 75 years (adjusted OR 2.1; 95\% Cl: 1.2, 3.5), and female gender (adjusted OR $1.7 ; 95 \% \mathrm{Cl}: 1.0,2.8)$.

\section{Discussion}

This study demonstrates that the STS Adult Cardiac Surgery database can be used to identify independent risk factors for leg harvest site infection in CABG patients. We have shown recently that this database is also a useful tool for identifying risk factors for deep and superficial chest infections in CABG patients. ${ }^{21}$ Use of the STS database for identification of risk factors for infectious and noninfectious complications in CABG patients has the advantage of routine ongoing collection of data for all cardiac surgery patients and the use of standardized definitions for the potential risk factors and outcomes. This makes the STS database a very useful tool for monitoring rates of complications and development of quality improvement programs.

\section{Independent Risk Factors as Predictors of Leg Harvest Site Infection}

Postoperative transfusion with 5 or more units of packed red blood cells, previous cerebrovascular accident, obesity, older age, and female gender were identified as independent risk factors for leg harvest site infections in our study. A history of cerebrovascular accident has not been identified previously as a risk factor for leg harvest site infection in CABG patients, although peripheral vascular disease ${ }^{14}$ and arterial occlusive disease of the legs ${ }^{13}$ have been reported to increase the risk of leg wound complications. The increased risk of leg harvest site infections in women in this study supports previous findings ${ }^{7,9}$ and may be due to gender differences in fat distribution or to more impaired peripheral circulation in women than in men.

Postoperative transfusion with 5 or more units of packed red blood cells was also associated with increased risk of leg harvest site infection in this study. Transfused blood products have been reported as risk factors of deep chest surgical site infections in CABG patients, ${ }^{21-23}$ but have not been reported previously as risk factors for leg harvest site infection, to our knowledge.

Obesity was also independently associated with both confirmed and total leg harvest site infections, confirming previous reports. ${ }^{6-8}$ Obesity may increase the risk of leg infections by a number of different mechanisms, including poor penetration of prophylactic antibiotics into adipose tissue, increased likelihood of poorly controlled serum glucose (with or without documentation of a diagnosis of diabetes), increased colonization of the skin with bacteria with associated difficulty in skin antisepsis at the time of surgery and in the postoperative period, and impaired wound healing after surgery. Obesity may be a risk factor for superficial infections in general at the site of a surgical incision, as it also has been shown to be associated with increased risk of superficial chest infections after $\mathrm{CABG}^{8,21}$ and all surgical site infections in cancer patients. ${ }^{24}$

Preoperative aspirin therapy had a protective effect against confirmed leg harvest site infections in this study but not total infections. This may be a reflection of the protective effect of aspirin in more severe infections. The infections in the 9 patients that could not be verified by the infection control specialist were all presumably diagnosed in the outpatient setting and were, most likely, minor superficial incisional infections. This apparent protective effect of aspirin therapy for more severe leg harvest site infections requires independent confirmation.

The combination of insulin-dependent diabetes and a history of cerebrovascular accident was associated with greater risk of leg harvest site infections than would be predicted based on the additive effects of the individual risk factors. The greatly increased risk of leg harvest site infection in individuals with both insulin-dependent diabetes and previous cerebrovascular accident may be due to the increased incidence of peripheral vascular disease in this subpopulation of patients compared with patients with neither pre-existing illness or to some unmeasured covariate.

\section{Effect of Leg Harvest Site Infection on Morbidity and Mortality}

Patients with leg harvest site infections (total infections) stayed an average 3.0 days longer in the hospital after surgery than patients with no identified infections in the 
month after CABG. Although this is a crude estimate of the attributable increase in length of hospital stay during the surgical admission, it suggests increased morbidity in patients with harvest site infections compared to uninfected patients. This estimate does not take into account the additional hospital days incurred during readmission(s) for treatment of infections in the patients with leg harvest site infections, and thus the attributable increase in total hospital length of stay is greater than determined in this study. There was no increase in mortality attributed to leg harvest site infection in this study, consistent with the observation that the majority of infections were superficial.

\section{Clinical Implications}

The ultimate goal of this type of epidemiologic study is to identify potential risk factor(s) and use this knowledge to design strategies to prevent postoperative infections. Although several of the risk factors identified in this study are not modifiable, such as female gender, older age, and history of cerebrovascular accident, strategies to reduce the risk of leg harvest site infections in these individuals can still be devised. Obese patients, particularly women with excessive fat distribution in the thighs, may benefit from higher doses of prophylactic antibiotics (ie, $2 \mathrm{~g}$ of cefazolin instead of $1 \mathrm{~g}$ ), since antibiotic penetration in fat is poor. ${ }^{25}$ Older patients and those with a history of cerebrovascular accident discharged to home may need follow-up by home health care nurses to ensure adequate local care at the site of the leg incision(s).

Several studies have been published that report a lower rate of leg harvest site infections or wound complications in patients whose saphenous vein(s) were harvested by endoscopic rather than conventional methods. ${ }^{711,15,18,19}$ Although only one of these studies randomized patients to either harvest method, ${ }^{11}$ the apparent association of a traditional method of harvest using a long incision with increased risk of infection is consistent with the observation that risk correlates with wound length. ${ }^{12}$ We could not test the association of harvest method with leg harvest site infection since the time period of the study predated the introduction of endoscopic harvest in our institution. It will be important to confirm the benefit of endoscopic harvest in reducing the risk of leg harvest site infection, particularly in patients at high risk for infection as identified in this study.

\section{Study Limitations and Strengths}

The principle limitation of this study is the relatively small number of outcome events, although the number of leg harvest site infections in our study is still larger than in almost all other published reports. As with all studies of surgical site infections, the number of superficial harvest site infections is probably underestimated due to the difficulty of identifying particularly those infections diagnosed in the outpatient setting. An additional limitation is the lack of information in the STS database about some potentially important predictor variables, such as the location and length of the leg incision and the time the leg wound was open, that have been associated with leg wound infections or complications in single reports. ${ }^{12,17}$

Our study benefits from the confirmation of $90 \%$ of the leg harvest site infections using NNIS criteria to verify the identification of deep and superficial leg harvest site infections. It is particularly important to confirm leg infections with standardized accepted criteria since the majority of infections were superficial and could not be confirmed by growth of bacteria in cultures obtained from the leg wound. The primary strengths of this study are its use of the STS database as the source of data and its use of the multivariate methods for analysis. Our institutional database contains a large quantity of information on potential risk factors in addition to potentially relevant variables not included in the national database, such as the number of units of transfused blood products and the duration of antibiotic prophylaxis, making it very useful for identification of risk factors for a variety of postoperative infections.

\section{Summary}

Leg harvest site infections are not uncommon in CABG patients after traditional harvest methods for collection of saphenous vein(s). Although most were classified as superficial, the harvest site infections were associated with increased morbidity and length of hospital stay for patients. Identification of independent risk factors for infection is important to develop strategies to prevent infection and to allow for recognition of patients at high risk who may need more careful monitoring for development of infections. The use of less invasive techniques, such as endoscopic vein harvest and expanded use of arterial grafting, may be helpful in decreasing the incidence of harvest site infection in high-risk patients.

We gratefully acknowledge the members of the Division of Cardiothoracic Surgery at Washington University who performed the operative procedures included in this study (Hendrick B. Barner, James L. Cox, T. Bruce Ferguson, Jr, William A. Gay, Jr, Charles Huddleston, Scott Johnson, Eric Mendeloff, Marc R. Moon, Kevin Murray, Michel K. Pasque, and Michael Rosenbloom). We also acknowledge the exceptional work of Tina Burmeister in managing our institutional STS database, and we thank Loretta Perry and Terry Leet for their comments.

\section{References}

1. Roy MC. Surgical-site infections after coronary artery bypass graft surgery: discriminating site-specific risk factors to improve prevention efforts. Infect Control Hosp Epidemiol. 1998;19:229-33.

2. Harbarth S, Samore MH, Lichtenberg D, Carmeli Y. Prolonged antibiotic prophylaxis after cardiovascular surgery and its effect on surgical site infections and antimicrobial resistance. Circulation. 2000; 101:2916-21. 
3. Spelman DW, Russo P, Harrington G, Davis BB, Rabinov M, Smith JA, et al. Risk factors for surgical wound infection and bacteraemia following coronary artery bypass surgery. Aust N Z J Surg. 2000;70: 47-51.

4. L'Ecuyer PB, Murphy D, Little JR, Fraser VJ. The epidemiology of chest and leg wound infections following cardiothoracic surgery. Clin Infect Dis. 1996;22:424-9.

5. DeLaria GA, Hunter JA, Goldin MD, Serry C, Javid H, Najafi H. Leg wound complications associated with coronary revascularization. J Thorac Cardiovasc Surg. 1981;81:403-7.

6. Engelman DT, Adams DH, Byrne JG, Aranki SF, Collins JJ Jr, Couper GS, et al. Impact of body mass index and albumin on morbidity and mortality after cardiac surgery. J Thorac Cardiovasc Surg. 1999;118: 866-73.

7. Carpino PA, Khabbaz KR, Bojar RM, Rastegar H, Warner KG, Murphy RE, et al. Clinical benefits of endoscopic vein harvesting in patients with risk factors for saphenectomy wound infections undergoing coronary artery bypass grafting. J Thorac Cardiovasc Surg. 2000;119:69-75.

8. Moulton MJ, Creswell LL, Mackey ME, Cox JL, Rosenbloom M. Obesity is not a risk factor for significant adverse outcomes after cardiac surgery. Circulation. 1996;94(Suppl II):87-92.

9. Vuorisalo S, Haukipuro K, Pokela R, Syrjala H. Risk features for surgical-site infections in coronary artery bypass surgery. Infect Control Hosp Epidemiol. 1998;19:240-7.

10. Mullen JC, Bentley MJ, Mong K, Karmy-Jones R, Lemermeyer G, Gelfand ET, et al. Reduction of leg wound infections following coronary artery bypass surgery. Can J Cardiol. 1999;15:65-8.

11. Kiaii B, Moon BC, Massel D, Langlois Y, Austin TW, Willoughby A, et al. A prospective randomized trial of endoscopic versus conventional harvesting of the saphenous vein in coronary artery bypass surgery. J Thorac Cardiovasc Surg. 2002;123:204-12.

12. Wong SW, Fernando D, Grant P. Leg wound infections associated with coronary revascularization. Aust N Z J Surg. 1997;67:689-91.

13. Utley JR, Thomason ME, Wallace DJ, Mutch DW, Staton L, Brown V, et al. Preoperative correlates of impaired wound healing after saphenous vein excision. J Thorac Cardiovasc Surg. 1989;98:147-9.

14. Paletta CE, Huang DB, Fiore AC, Swartz MT, Rilloraza FL, Gardner
JE. Major leg wound complications after saphenous vein harvest for coronary revascularization. Ann Thorac Surg. 2000;70:492-7.

15. Allen KB, Heimansohn DA, Robison RJ, Schier JJ, Griffith GL, Fitzgerald EB, et al. Risk factors for leg wound complications following endoscopic versus traditional saphenous vein harvesting. Heart Surg Forum. 2000;3:325-30.

16. Utley JR, Leyland SA, Johnson HD, Morgan MS, Wilde CM, Bell MS, et al. Correlation of preoperative factors, severity of disease, type of oxygenator, and perfusion times with mortality and morbidity of coronary bypass. Perfusion. 1991;6:15-22.

17. Goldsborough MA, Miller MH, Gibson J, Creighton-Kelly S, Custer CA, Wallop JM, et al. Prevalence of leg wound complications after coronary artery bypass grafting: determination of risk factors. Am J Crit Care. 1999;8:149-53.

18. Davis Z, Jacobs HK, Zhang M, Thomas C, Castellanos Y. Endoscopic vein harvest for coronary artery bypass grafting: technique and outcomes. J Thorac Cardiovasc Surg. 1998;116:228-35.

19. Bitondo JM, Daggett WM, Torchiana DF, Akins CW, Hilgenberg AD, Vlahakes CJ, et al. Endoscopic versus open saphenous vein harvest: a comparison of postoperative wound complications. Ann Thorac Surg. 2002;73:523-8.

20. Hosmer DW, Lemeshow S. Applied logistic regression. 2nd ed. New York: John Wiley; 2000.

21. Olsen MA, Lock-Buckley P, Hopkins D, Polish LB, Sundt TM, Fraser VJ. The risk factors for deep and superficial chest surgical-site infections after coronary artery bypass graft surgery are different. $J$ Thorac Cardiovasc Surg. 2002;124:136-45.

22. Zacharias A, Habib RH. Factors predisposing to median sternotomy complications. Deep versus superficial infection. Chest. 1996;110: 1173-8.

23. Ottino G, De Paulis R, Pansini S, Rocco G, Tallone MV, Comoglioi C, et al. Major sternal wound infection after open-heart surgery: a multivariate analysis of risk factors in 2579 consecutive operative procedures. Ann Thorac Surg. 1987;44:173-9.

24. Barber GR, Miransky J, Brown AE, Coit DG, Lewis FM, Thaler HT, et al. Direct observations of surgical wound infections at a comprehensive cancer center. Arch Surg. 1995;130:1042-7.

25. Forse RA, Karam B, MacLean LD, Christou NV. Antibiotic prophylaxis for surgery in morbidly obese patients. Surgery. 1989;106:750-7. 